\title{
Effect of ambient temperature on recovery from muscular exercise
}

\author{
*J. Amarasena', A.A.J. Rajaratne ${ }^{2}$, P. Balasuriya ${ }^{2}$, N. Amarasena ${ }^{3}$ \\ The Ceylon Journal of Medical Science 2004; 47: 29-36
}

\begin{abstract}
Sri Lanka has high daytime ambient temperatures throughout the year that are too high to allow dissipation of body heat by non-evaporative methods. The predominant method of heat loss in the tropics, the evaporative heat loss, is also limited because of high humidity caused by wet conditions. Therefore, the limitations to thermoregulation could lead to poor work performance.
\end{abstract}

This study was aimed at investigating the effect of two different ambient temperatures $\left(28.5^{\circ} \mathrm{C}\right.$ with relative humidity of $73.4 \%$ and $22.6^{\circ} \mathrm{C}$ with relative humidity of $64 \%$ ) on the recovery from muscular exercise. The study was conducted on 20 sedentary male university students aged 21-24 years (mean 22.5 years). They were made to perform standard exercise for six minutes on a bicycle ergometer at two different ambient temperatures on two different occasions. Physiological parameters including heart rate, pulmonary ventilation, axillary temperature, systolic and diastolic blood pressures were measured at rest and during recovery at five-minute intervals up to 20 minutes. Results showed that although the recovery pattern of cardio-respiratory changes were similar at these two ambient temperatures, the values for heart rate, pulmonary ventilation and systolic blood pressure at the end of exercise at higher ambient temperature with higher relative humidity were significantly higher.

At least in the study situation, the lower ambient temperature would be more favourable with regard to cardio-respiratory changes while performing moderate exercise. These findings point to the importance of planning different schedules of work and resting periods for different environmental conditions, especially, those with high ambient temperature and high relative humidity.

Key words: Ambient temperature, muscular exercise

\section{Introduction}

Notwithstanding the recent advances in technology and protective equipment, people are still required to perform a wide range of activities under different forms of thermal stress, often in combination with other stressors. Heavy physical work is obligatory in numerous occupations including commercial fishing, agriculture,

1. Division of Physiology, Department of Basic Sciences, Faculty of Dental Sciences, University of Peradeniya, Sri Lanka.

2. Department of Physiology, Faculty of Medicine, University of Peradeniya, Sri Lanka.

3. Ministry of Health.

\section{*Author for correspondence}

E-mail: jayanthaa@pdn.ac.lk 
forestry, construction, transportation as well as in many service occupations. The optimal operation of the functional unit of the working place and the worker depends to a large extent on the mutual adaptation of the worker to his task, and in achieving such adaptation some basic physiological functions need to be fulfilled optimally. In real life situations, however, many occupations in hot environments involve alternating periods of work and rest. Accordingly, in hot environments workers tend to withdraw themselves from the sources of heat and rest in a cool environment. Studies on animal models (1) and humans (2) have shown that physical performance in the heat is limited by the attainment of a critical internal temperature. In addition, some human studies revealed differences in cardio-respiratory changes during exercise in different ambient temperatures $(3,4,5,6)$. Although, these types of studies have been carried out in countries where seasonal variations prevail such information is scarce in tropical countries like Sri Lanka.

Being a tropical country, Sri Lanka does have high daytime ambient temperatures throughout the year, compared to the comfortable ambient temperatures that allow dissipation of body heat by non-evaporative methods. The heat loss by evaporation is also limited by high humidity owing to wet conditions. Therefore, such limitations to thermoregulation could inevitably lead to poor work performance. The present study was conducted with the objective of investigating the effect of two different ambient temperatures on the recovery from a standard exercise in a group of sedentary young males.

\section{Methodology}

Ethical clearance for the study was obtained from the Research, Ethical Review and Higher Degrees Committee of the Faculty of Dental Sciences, University of Peradeniya. Informed consent was obtained from each subject prior to the study having explained the purpose of the study, extent of involvement, any known risks and the right to terminate participation at will. The study was conducted on 20 healthy, sedentary male undergraduate volunteer students.

The data were collected from each subject: between $2.00-4.00 \mathrm{pm}$ in two different rooms- the laboratory and the airconditioned room, at two different ambient temperatures.

The average time difference between performing two experiments was approximately 14 days. The ambient temperature of the room was determined using the reading of the dry bulb thermometer. Relative humidity was obtained from using dry and wet bulb thermometer readings and a nomogram, which was designed for use in calm conditions that exist in environments such as inside the buildings (7). The mean ambient temperature of the laboratory was $28.5 \pm 1.16^{\circ} \mathrm{C}$ and the relative humidity was $73.4 \% \pm 5.37 \%$. The mean ambient temperature of the air-conditioned room was $22.6 \pm 1.19^{\circ} \mathrm{C}$ and the relative humidity was $64 \% \pm 4.47 \%$. The subjects were advised not to engage in any heavy physical activity or smoking during the two-hour period prior to the test.

After resting for a period of 20 minutes, the subject was made to sit on the bicycle 
ergometer and the height of the seat was adjusted to a comfortable position. The functioning of the ergometer was demonstrated and the performance of the test was explained. The following measurements were obtained.

The ECG (Cardisuny 501 D) lead I was recorded for estimation of heart rate. Records were taken for a period of 15 seconds and heart rate was calculated from $R-R$ interval. Respiratory rate and depth were recorded over a period of one minute using a Palmer Water-seal multipurpose recording spirometer and pulmonary ventilation was calculated. A thermocouple (Terumo electro thermometer NO A 8408) was used to measure the axillary temperature: A probe was placed in the axilla using a tape wrapped around the upper arm. The subject was advised to keep the probe in touch with the axilla all the time. The blood pressure was measured at the brachial artery by the auscultatory method using a sphygmomanometer.

Then the subject pedalled the ergometer for 6 minutes at a fixed workload of $120 \mathrm{~W}$ at $50 \mathrm{rpm}$. Thereafter, he continued to sit on the bicycle ergometer for 20 minutes until measurements were taken during recovery from exercise. All the above measurements were recorded at the end of exercise i.e., at 0 minute and thereafter at 5 minute intervals for a period of 20 minutes. The methodology has been described in detail elsewhere (8).

\section{Statistical analysis}

One-way ANOVA and post hoc Tukey tests were used to compare the differences between the resting and recovery values for each parameter at a given ambient temperature and Student's paired t-test was used to compare the differences between the corresponding values for each parameter at the two different ambient temperatures. The statistical significance was accepted at $P_{<}$ 0.05 .

\section{Results}

The mean age, height and weight of the study sample were $22.5 \pm 0.94$ years, $165.9 \pm 3.94 \mathrm{~cm}$ and $53.8 \pm 5.72 \mathrm{~kg}$, respectively. The changes of variables tested at the two temperatures are given in Tablesland 2. The mean resting heart rate at $28.5^{\circ} \mathrm{C}$ was not significantly different from that at $22.6^{\circ} \mathrm{C}(\mathrm{P}>0.05$, paired $\mathrm{t}$-test $)$. The mean heart rate at 0 minute was significantly higher than that at rest at both ambient temperatures $(P<0.05$, one-way ANOVA and Tukey test). There was a significantly higher mean heart rate at 0 minute at $28.5^{\circ} \mathrm{C}$ when compared to $22.6^{\circ} \mathrm{C}(\mathrm{P}<0.05)$. At both ambient temperatures the mean heart rate did not return to the resting value even at 20th minure and was significantly higher than that at rest $(\mathrm{P}<0.05)$.

The mean resting pulmonary ventilation at $28.5^{\circ} \mathrm{C}$ was higher than that at $22.6^{\circ} \mathrm{C}$, but the difference was not significant $(P>0.05)$. The mean pulmonary ventilation at 0 minute was significantly higher than that at rest at both ambient temperatures $(P<0.05)$. There was a significantly higher mean pulmonary ventilation at 0 minute, at $28.5^{\circ} \mathrm{C}$, when compared to $22.6^{\circ} \mathrm{C}(\mathrm{P}<$ 0.05 ). The mean pulmonary ventilation at the 10th minute was not significantly different from the resting values at both ambient temperatures $(P>0.05)$.

The mean axillary temperature at rest was significantly higher at $28.5^{\circ} \mathrm{C}$ when compared to $22.6^{\circ} \mathrm{C}(\mathrm{P}<0.05)$. At $28.5^{\circ} \mathrm{C}$, 
Table 1. Mean values for each parameter at rest and during recovery at $28.5^{\circ} \mathrm{C}$

\begin{tabular}{lllllll}
\hline & Rest & \multicolumn{5}{c}{ Recovery } \\
\cline { 3 - 7 } & & $0 \mathrm{~min}$ & $5 \mathrm{~min}$ & $10 \mathrm{~min}$ & $15 \mathrm{~min}$ & $20 \mathrm{~min}$ \\
\hline HR & $80.6(12)$ & $166.6(16)^{*}$ & $116.2(14)^{*}$ & $108.9(8)^{*}$ & $106.5(10)^{*}$ & $103.8(9)^{*}$ \\
PV & $10.5(3)$ & $39.6(8)^{*}$ & $16.2(4)^{*}$ & $12.3(3)$ & $11.1(3)$ & $10(2)$ \\
Axil & $36.53(0.3)$ & $36.96(0.4)^{*}$ & $36.88(0.2)^{*}$ & $36.79(0.2)^{*}$ & $36.75(0.3)$ & $36.73(0.3)$ \\
SBP & $115.1(5)$ & $150.5(9)^{*}$ & $128.6(9)^{*}$ & $118.3(7)$ & $115.4(7)$ & $115.3(6)$ \\
DBP & $76.4(7)$ & $80.3(8)$ & $78.2(8)$ & $78.1(7)$ & $77.2(8)$ & $76.3(8)$ \\
\hline
\end{tabular}

* Indicates a significant difference between rest and recovery ( $P<0.05$, one-way ANOVA and Tukey). $\mathrm{HR}=$ heart rate, $\mathrm{PV}=$ pulmonary ventilation, Oral=oral temperature, Axil=axillary temperature, $\mathrm{SBP}=$ systolic blood pressure, $\mathrm{DBP}=$ diastolic blood pressure: Standard deviations are indicated in parentheses.

$\mathrm{HR}$ is expressed as beats/min.

The temperature is measured in degrees of Centigrade.

$\mathrm{BP}$ is measured in $\mathrm{mmHg}$.

$\mathrm{PV}$ is measured in $\mathrm{L} / \mathrm{min}$.

Table 2. Mean values for each parameter at rest and during recovery at $22.6^{\circ} \mathrm{C}$

\begin{tabular}{lllllll}
\hline & Rest & \multicolumn{5}{c}{ Recovery } \\
\cline { 3 - 7 } & & 0 min & 5 min & $10 \min$ & 15 min & 20 min \\
\hline HR & $80.1(12)$ & $148.4(31)^{*}$ & $113.4(17)^{*}$ & $107.1(17)^{*}$ & $103.6(16)^{*}$ & $97.9(16)^{*}$ \\
PV & $9.1(3)$ & $28.5 .1(10)^{*}$ & $15.2(5)^{*}$ & $11.9(3)$ & $10.5(4)$ & $9.9(3)$ \\
Axil & $36.31(2.7)$ & $36.73(0.5)$ & $36.65(0.5)$ & $36.58(0.5)$ & $36.50(0.5)$ & $36.4(0.4)$ \\
SBP & $116.9(5)$ & $141.7(16)^{*}$ & $127.5(11)^{*}$ & $121.1(6)$ & $117.6(5)$ & $115.9(6)$ \\
DBP & $76.3(5)$ & $77.1(6)$ & $76(7)$ & $75.8(7)$ & $75.3(7)$ & $75.6(7)$ \\
\hline
\end{tabular}

* Indicates a significant difference between rest and recovery $(P<0.05$, one-way ANOVA and Tukey). $\mathrm{HR}=$ heart rate, $\mathrm{PV}=$ pulmonary ventilation, Oral=oral temperature, Axil=axillary temperature, $\mathrm{SBP}=$ systolic blood pressure, $\mathrm{DBP}=$ diastolic blood pressure: Standard deviations are indicated in parentheses.

$\mathrm{HR}$ is expressed as beats/min.

The temperature is measured in degrees of Centigrade.

$\mathrm{BP}$ is measured in $\mathrm{mmHg}$.

$\mathrm{PV}$ is measured in $\mathrm{L} / \mathrm{min}$. 
the mean axillary temperature at $\mathbf{0}$ minute was significantly higher than that at rest and remained so even at the $10^{\text {th }}$ minute after stopping exercise $(P<0.05)$. The mean axillary temperature at $20^{\text {th }}$ minute was significantly higher at $28.5^{\circ} \mathrm{C}$ when compared to $22.6^{\circ} \mathrm{C}(\mathrm{P}<0.05)$. At $22.6^{\circ} \mathrm{C}$, there was no significant change in the mean resting axillary temperature at 0 minute or during recovery $(P>0.05)$.

The mean resting systolic blood pressure (SBP) at $28.5^{\circ} \mathrm{C}$ was higher than that at $22.6^{\circ} \mathrm{C}$, but the difference was not significant (P>0.05). The mean SBP at 0 minute was. significantly higher than that at rest at both ambient temperatures $(\mathrm{P}<0.05)$. There was a significantly higher mean SBP at 0 minute at $28.5^{\circ} \mathrm{C}$ when compared to that at $22.6^{\circ} \mathrm{C}$ $(\mathrm{P}<0.05)$. The mean SBP at the $10^{\text {th }}$ minute was not significantly different from the mean resting SBP at both ambient temperatures (P>0.05).

There was no significant difference between the mean diastolic blood pressure (DBP) at $28.5^{\circ} \mathrm{C}$ and that at $22.6^{\circ} \mathrm{C}(\mathrm{P}<0.05)$. At both ambient temperatures, there were no significant differences between the mean DBP at rest and during recovery up to $20^{\text {th }}$ minute $(P<0.05)$.

\section{Discussion}

In Sri Lanka, the average daytime ambient temperature that exists inside buildings is around $28.5^{\circ} \mathrm{C}$ and the relative humidity is $73.4 \%$ and the majority of indoor workers operate in such environments in their daily work. A minority is working in airconditioned environments where the ambient temperature is around $22.6^{\circ} \mathrm{C}$ and the relative humidity is $64 \%$. Accordingly, we selected $22.6^{\circ} \mathrm{C}$ and $28.5^{\circ} \mathrm{C}$ ambient temperatures for the present study and, therefore, the present findings may be applied only for such working environments. The findings revealed that although the recovery pattern was similar at both ambient temperatures the values for heart rate, pulmonary ventilation and systolic blood pressure at 0 minute at $28.5^{\circ} \mathrm{C}$ were significantly higher when compared to those at $22.6^{\circ} \mathrm{C}$. Therefore, it could be stated that at least in the study situation, the lower ambient temperature with lower relative humidity would be more favourable with regard to cardio-respiratory changes while performing moderate exercise.

The present study sample comprised first year, male undergraduate students who were engaged in their studies most of the time without much physical activity. Having excluded the effects of training and gender bias, it could be plausible that any differences obtained were mainly due to the effect of ambient temperature and relative humidity. Also, it is important to consider the fact that this study was carried out by selecting a volunteer group of healthy young males who were highly motivated and subjected to relatively brief periods of exposure to a particular exercise protocol. However, the everyday or real life occupational situations may differ considerably. On the other hand, a laboratory experiment (ie. the exercise) can create an atmosphere which is much more stressful than that of a routine occupational situation owing to the artificial environment that exists.

We noticed a significantly higher axillary temperature at rest and at $20^{\text {th }}$ minute at $28.5^{\circ} \mathrm{C}$ compared to those at $22.6^{\circ} \mathrm{C}$. This indicates that the axillary temperature at rest is increased at higher ambient temperatures 
with high relative humidity due to heat gain mechanisms. This finding is in line with the other studies pointing that axillary temperature is a reliable measure like the rectal temperature, which is known to be the closest to the core temperature (9). On the other hand, sweating can affect the readings of axillary temperature, especially at higher ambient temperatures, and thus the actual values for ambient temperature at $28.5^{\circ} \mathrm{C}$ would have been much higher, in particular, during the early stages of recovery where rather profuse sweating could occur. A significantly higher axillary temperature at $20^{\text {th }}$ minute at $28.5^{\circ} \mathrm{C}$ compared to that at $22.6^{\circ} \mathrm{C}$ indicates that sweating might have subsided by $20^{\text {th }}$ minute of recovery and it would no longer have an effect on the readings of axillary temperature.

Cardio-respiratory changes observed in the present study may be related to attainment of higher body temperature at higher ambient temperature with higher relative humidity. The heart rate at 0 minute was significantly higher than that at rest at both ambient temperatures. This is due to factors like sympatheric stimulation, chemorecepror activity and proprioceptive impulses during muscular exercise. The significantly higher heart rate at 0 minute at $28.5^{\circ} \mathrm{C}$ compared to that at $22.6^{\circ} \mathrm{C}$ might indicate that the increase in heart rate at $28.5^{\circ} \mathrm{C}$ was due to attainment of a higher body temperature by lower heat dissipation in a hot, humid environment. Higher heart rate during recovery from exercise at the higher ambient temperature is in conformity with the results of other studies despite the fact that they used a wider range of ambient temperatures compared to ours $(5,8,10,12,13)$. At 20 th minute of recovery the heart rate had not returned to the resting value at both ambient temperatures. As the recovery time (time to regain the initial level) was longer than 20 minutes and the heart rate remained significantly higher than that at rest at both ambient temperatures, it can be assumed that the recovery pattern of heart rate is approximately similar at the two ambient temperatures.

The pulmonary ventilation at 0 minute was significantly higher than at rest at both ambient temperatures. This is due to metabolic acidosis and chemoreceptor stimulation during exercise. The finding of a significantly higher pulmonary ventilation at 0 minute at $28.5^{\circ} \mathrm{C}$ when compared to $22.6^{\circ} \mathrm{C}$ indicates that the higher pulmonary ventilation may be due to a higher body temperature. This finding is in conformity with the findings reported by Dimri et al. (14) and Gupta et al. (10) although they used a different range of ambient temperatures. At $10^{\text {th }}$ minute at both ambient temperatures, the pulmonary ventilation returned to resting values indicating that recovery pattern of pulmonary ventilation was similar at $28.5^{\circ} \mathrm{C}$ and $22.6^{\circ} \mathrm{C}$ ambient temperatures. These findings are in conformity with those of Chapman et al. (3) although they used a wider range of ambient temperatures $\left(20^{\circ} \mathrm{C}\right.$ to $\left.-11^{\circ} \mathrm{C}\right)$ compared to our study.

SBP at the end of exercise was significantly higher than that at rest at both ambient temperatures. During exercise, venous return increases due to the action of muscle pump and respiratory pump. In addition, redistribution of blood reduces circulation to other areas and increases blood flow to exercising muscles. Because of increased venous return and heart rate, SBP is raised. As a result of the vasodilatation in the vascular bed in the active muscle, the peripheral resistance to blood flow is reduced 
during exercise, but the elevation in cardiac output causes the $S B P$ to rise. A significantly higher SBP at 0 minute at $28.5^{\circ} \mathrm{C}$ when compared to $22.6^{\circ} \mathrm{C}$ could be attributed mainly to higher heart rate at $28.5^{\circ} \mathrm{C}$ compared to that at $22.6^{\circ} \mathrm{C}$ as explained in the section on heart rate. At both ambient temperatures, at the 10th minute of recovery, SBP returned to resting values. Paradoxically, Franklin et al. (15) observed reduced SBP during recovery even up to 60 minutes after the cessation of exercise. The selected range of ambient temperatures and the workload in the present study were different from their study. Consequently, such conflicting findings could be ascribed to these methodological differences. According to the present findings, SBP during recovery was affected similarly at both ambient temperatures.

There was not a single statistically significant finding in relation to DBP in both ambient temperatures even though $\mathrm{DBP}$ at $28.5^{\circ} \mathrm{C}$ was higher when compared to $22.6^{\circ} \mathrm{C}$ at rest and throughout the recovery period up to 20 minutes. Franklin et al. (15) also reported that there was no significant difference between baseline and post-exercise measurements of DBP at 3 different ambient temperatures $\left(17^{\circ} \mathrm{C}, 21^{\circ} \mathrm{C}\right.$ and $\left.31^{\circ} \mathrm{C}\right)$. It is known that the DBP, when measured with a blood pressure cuff, is constant or falls slightly with increasing rate of exercise. The cuff method apparently gives a slightly different picture than the intra-vascular recording of the diastolic blood pressure (16). In the present study blood pressure was measured by the cuff method. Accordingly, the variations seen in diastolic blood pressure may have resulted from the methodology used. In other studies also the DBP has showed only small changes (17).
In conclusion, within the limitations of the study, the present findings showed that although ambient temperatures $28.5^{\circ} \mathrm{C}$ and $22.6^{\circ} \mathrm{C}$ had almost a similar effect on the recovery from a standard exercise, the values for heart rate, pulmonary ventilation and systolic blood pressure just after exercise at the higher ambient temperature were significantly higher. These findings point to the importance of planning different schedules of work and resting periods for environmental conditions with high ambient temperature and high relative humidity as well as low ambient temperature and low relative humidity and maintaining a comfortable temperature wherever possible to reduce the stress on the cardio-respiratory system.

\section{Acknowledgements}

The authors are grateful to Professor M. Udupihille and Dr. V. S. Weerasinghe of the Department of Physiology, Faculty of Medicine, University of Peradeniya and the Research, Ethical Review and Higher Degrees Committee of the Faculty of Dental Sciences, University of Peradeniya, for funding the study. Mr S. C. Dissanayake is thanked for technical assistance.

\section{References}

1. Walters T.J., Ryan K.L., Tate L.M., Mason P.A. Exercise in the hear is limited by a critical internal temperature. Journal of Applied Physiology 2000; 89:799-806.

2. Haragreaves M., Febbraio M. Limits to exercise performance in the heat. International Journal of Sports Medicine 1998;19:S115-116. 
3. Chapman K.R., Allen L.J., Romet T.T. Pulmonary functions in normal subjects following exercise at cold ambient temperatures. European Journal of Applied Physiology and Occupational Physiology 1990;60: 228-232.

4. Galloway S.D., Maughan R.J. Effects of ambient temperature on the capacity to perform prolonged cycle exercise in man. Medicine and Science in Sports and Exercise 1997,285: 1240-1249.

5. Leweke F., Bruck K., Olschewski $H$. Temperature effects on ventilatory rate, heart rate, and preferred pedal rate during cycle ergometry. Journal of Applied Physiology 1995;79: 781-785.

6. Pekkarinen $H$., Tukiainen $H$., Litmanen H., Huttunen J., Karstu T., Lansimies E. Effect of submaximal exercise at low temperatures on pulmonary function in healthy young men. European Journal of Applied Physiology and Occupational Physiology 1989;58:821-825.

7. Bell G.H., Weir J.B. Nomograms for relative humidity. British Medical Journal 1947;4517:174.

8. Amarasena J.K.C. Some factors affecting the efficiency of and recovery from muscular exercise. M.Phil Thesis; 1997, University of Peradeniya.

9. Dharmarajan A.M., Perera K.M.H., Thangarajan S.A. The relationship between rectal and axillary temperature in children. Indian Journal of Physiology and Pharmacology 1982;26: 101-102.

10. Gupta J.S., Swamy Y.V., Dimiri G.P., Pichan G. Physiological responses during work in hot humid environments. Indian Journal of Physiology and Pharmacology 1981;25:339-347.

11. Irondelle M., Freund H. Carbohydrate and fat metabolism of unacclimatized men during and after submaximal exercise in cool and hot environments. European Journal of Applied Physiology and Occupational Physiology 1977;37:27-38.

12. Kruk B., Pekkarinen H., Mannien K., Hanninen O. Comparison in men of physiological responses to exercise of increasing intensity at low and moderate ambient temperature. European Journal of Applied Physiology and Occupational Physiology 1991;62:353-357.

13. Sen Gupta J., Dimri G.R., Malhotra M.S. Metabolic responses of Indians during submaximal work in dry and humid heat. Ergonomics 1977;20: 3340.

14. Dimri G.P., Malhotra M.S., Sen Gupta J., Sampath Kumar T., Arora B.S. Alteration in aerobic-anaerobic propotions of metabolism during work in heat. European Journal of Applied Physiology and Occupational Physiology 1980;45:43-50.

15. Franklin P.J., Green D.J., Cable N.T. The influence of thermoregulatory mechanisms on post-exercise hypotension in humans. Journal of Physiology 1993;470: 231-241.

16. Astrand P.O., Radahl K. Textbook of work physiology. McGraw hill International Edition 1986; P285-390.

17. Palatini P. Blood pressure behaviour during physical activity. Sports Medicine 1988; 5: 353-374. 